\title{
Teletalker - Making Online Face-to-Face Interaction Easier for Older People
}

\author{
Marianne Markowski and Dominique Rivoal \\ Middlesex University \\ Lansdown Centre for Electronic Arts \\ UK \\ marianne@teletalker.org, d.rivoal@mdx.ac.uk
}

\section{DEMONSTRATION OF THE TELETALKER}

In this demonstration I will be conveying the aims of my Teletalker research by having a conversation (through the Teletalker) with our technician Dominique Rivoal at another location.

This conversation will involve an explanation of why I built the Teletalker employing constructive design research (Koskinen et al. 2011) as my method. During this conversion I will explain the reasons for using Constructive Design Research when building the Teletalker.

The Teletalker has been developed to make faceto-face communication online easier for older people and to demonstrate the benefits of online connectivity (Melenhorst et al. 2006, Blažun et al. 2012). The Teletalker system is an installation of two 'kiosks' connecting two places using Skype, appearing to work like an online window. The appearance of the Teletalker, which houses the screens, computers, speakers, cameras and microphones, was originally chosen to be in the style of 1930-50 Television sets.

The updated version of the Teletalker, i.e. the second prototype, is more compact and the design now includes wheels for added mobility and a bell to ring for attention. The second prototype will be used in field research by connecting two London care homes for the residents to get to know each other prior to the merger of the two homes.

The Teletalker's appearance is intended to be not overtly technical. The design aims to be simple and allows usage by small groups of people on each side. The Teletalker includes a simple hand mechanism to activate the volume (which is 'off' by default), so that one can speak into it and have a conversation with a person at the other location.

This mechanism has been chosen with an older person in mind, who may not be computer literate and who may have limited dexterity. The Teletalker aims to be intuitive, evoke curiosity around technology in a playful manner and enable people of all ages to interact live online (Romero et al. 2010). Choosing where to place the two Teletalker kiosks is integral to my research as well as its ability to generate a discussion around the forms of online social interaction technology for older people. After the demonstration people are invited to try the Teletalker out and give feedback.

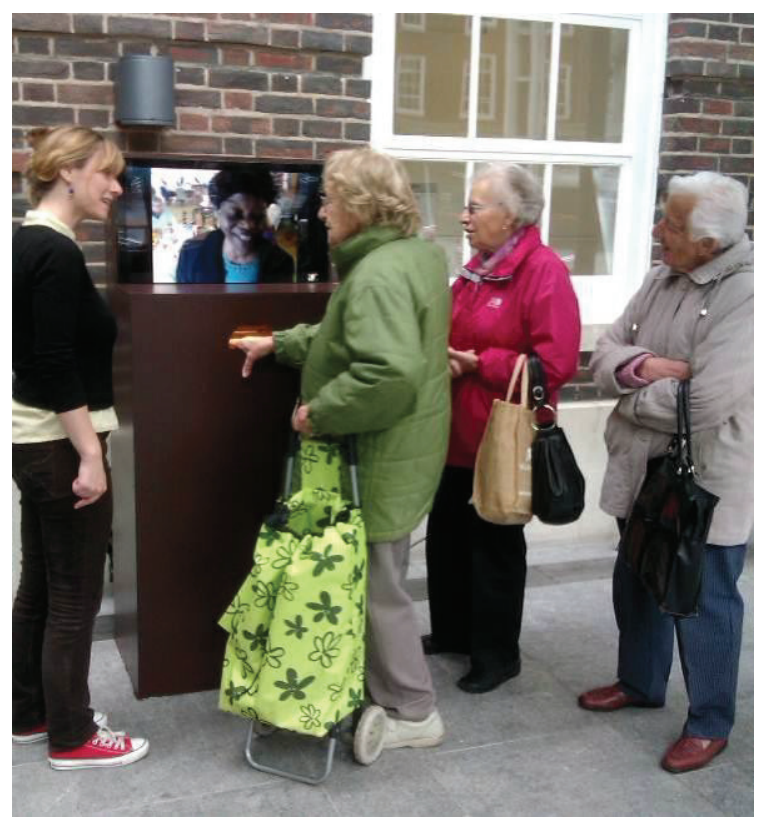

Figure 1: A group of older people using the Teletalker at Middlesex University speaking to a person at Age UK Barnet during field research in June 2012 


\section{REFERENCES}

Blažun, H., Saranto, K., and Rissanen, S. (2012) "Impact of computer training courses on reduction of loneliness of older people in Finland and Slovenia," Computers in Human Behavior, vol. 28, no. 4, pp. 1202-1212, Jul. 2012.

Koskinen, I., Zimmerman, J. , Binder, T., Redstrom, J., and Wensveen, S. (2011) Design Research Through Practice: From the Lab, Field, and Showroom. Morgan Kaufmann, 2011.

Melenhorst, A.-S., Rogers, W. A., and Bouwhuis D. G. (2006) 'Older adults' motivated choice for technological innovation: evidence for benefitdriven selectivity.," Psychology and aging, vol. 21, no. 1, pp. 190-5, Mar. 2006.
Romero, N., Sturm, J., Bekker, T., De Valk, L., Kruitwagen, S., and de Valk, L. (2010) "Playful persuasion to support older adults' social and physical activities," Interacting with Computers, vol. 22, no. 6, pp. 485-495, Nov. 2010. 